\title{
Be Aware of Intrapulmonary Percussive Ventilation
}

Many patients who need airway clearance therapies are also prescribed inhaled therapies. Different clinical scenarios include patients receiving invasive ventilatory support and others who are not. The latter group can use a positive expiratory pressure or oscillating positive expiratory pressure device that allows concurrent airway clearance and nebulization without affecting aerosol characteristics. ${ }^{1}$ These patients can also use intrapulmonary percussive ventilation (IPV). ${ }^{2,3}$ Previous studies have reported that IPV generates a submicronic aerosol and that it was an inefficient delivery device. ${ }^{4,5}$ Reychler et $\mathrm{al}^{4}$ reported that, in healthy adults, IPV produced lower lung deposition $(2.5 \%)$ of a radiolabeled aerosol and had more interindividual variability (104\%) than a jet nebulizer. In another study, ${ }^{5}$ investigators reported $0.8 \%$ and $5.6 \%$ intrapulmonary deposition for IPV and for a jet nebulizer, respectively, measuring urinary excretion of amikacin.

Patients receiving invasive mechanical ventilation have limited options for combined airway clearance and inhaled therapies. They could use inline aerosol administration while receiving high-frequency chest oscillation, or they could use IPV. A study using an adult model reported that superimposing IPV with conventional mechanical ventilation can result in auto-PEEP and an increase in tidal volume. ${ }^{6}$ Another study using a pediatric model with IPV reported low aerosol delivery and no difference between IPV operation in easy or hard settings. ${ }^{7}$

Information regarding the drug delivery of aerosols generated by IPV in patients receiving mechanical ventilation are limited. ${ }^{7}$ We welcome newer information to better understand how IPV can be used to deliver aerosols. In this issue of ResPiratory CARE, Karashima et $\mathrm{al}^{8}$ publish an in vitro study about albuterol delivery in a model of an intubated adult. The authors delivered IPV at different pressures and frequencies, of operation, and they used a model that could replicate different respiratory mechanics.

\footnotetext{
Dr Berlinski has disclosed relationships with Cempra Therapeutics, Mylan, Novartis, Vertex, Abbvie, Aptalis, Therapeutic Development Network, National Institutes of Health, and Trudell Medical International.

Correspondence: Ariel Berlinski MD FAARC, University of Arkansas for Medical Sciences, Department of Pediatrics, Pulmonary Medicine, 1 Children's Way, Slot 512-17, Little Rock, AR 72202. E-mail: berlinskiariel@uams.edu.
}

DOI: $10.4187 /$ respcare. 07049
They used IPV connected to the endotracheal tube but not connected to the ventilator circuit. The authors reported albuterol delivery after the endotracheal tube between $0.4 \%$ and $2 \%$ for each of the tested conditions. ${ }^{8}$

See the Original Study on Page 502

Karashima and colleagues found that the addition of the endotracheal tube resulted in a decrease in output from $2.8 \%$ to $2 \%$ (see article Fig. 1, filters A and B). They also reported that the ventilator of the phasitron lost $15.2 \%$ of the aerosol (see article Fig. 1, filter C). Unfortunately, the authors did not perform a mass balance, and $80 \%$ of the aerosol was unaccounted for. The authors reported an increase in albuterol delivery when the IPV settings were changed from easy to hard, which resulted in higher tidal volumes. ${ }^{8}$ These results contradict previous data that found no difference between the easy and hard settings in a pediatric model using IPV superimposed with conventional mechanical ventilation. ${ }^{7}$ Differences in investigational setup might explain these differences. Karashima et $\mathrm{al}^{8}$ also reported that when the respiratory mechanics were set at high resistance, albuterol delivery decreased regardless of the compliance. They also found that high peak inspiratory pressures, even up to $80 \mathrm{~cm} \mathrm{H}_{2} \mathrm{O}$, occurred during IPV therapy. These data are in agreement with those of Dellamonica et $\mathrm{al}^{6}$ and should serve as warning that these patients must be carefully monitored for the development of complications.

One problem with translating these findings into clinical practice is that the IPV configuration used by the authors required breaking the circuit. This practice carries 2 potential problems: increasing the risk for ventilator-associated pneumonia, and potential lung de-recruitment in patients ventilated with high PEEP..$^{9,10}$ Other studies using the manufacturer's adapter, which allows the operation of the device without disconnecting the patient from the ventilator circuit, provided information that could be used for patients who are not good candidates for disconnection from the ventilator circuit. 6,7

In summary, this study increases our knowledge regarding aerosol delivery with IPV in patients receiving invasive mechanical ventilation. The findings confirm that IPV provides inefficient drug delivery, and that it should be carefully used in these populations due to the reported 


\section{EDITORIALS}

increase in pressures that could result in the development of barotrauma.

Ariel Berlinski

University of Arkansas for Medical Sciences Department of Pediatrics, Pulmonology Section, and Pediatric Aerosol Research Laboratory Arkansas Children's Research Institute Little Rock, Arkansas

\section{REFERENCES}

1. Berlinski A. In vitro evaluation of positive expiratory pressure devices attached to nebulizers. Respir Care 2014;59(2):216-222.

2. Natale JE, Pfeifle J, Homnick DN. Comparison of intrapulmonary percussive ventilation and chest physiotherapy: a pilot study in patients with cystic fibrosis. Chest 1994;105(6):1789-1793.

3. Homnick DN, White F, de Castro C. Comparison of effects of an intrapulmonary percussive ventilator to standard aerosol and chest physiotherapy in treatment of cystic fibrosis. Pediatr Pulmonol 1995; 20(1):50-55.

4. Reychler G, Keyeux A, Cremers C, Veriter C, Rodenstein DO, Liistro G. Comparison of lung deposition in two types of nebulization: intrapulmonary percussive ventilation vs jet nebulization. Chest 2004; 125(2):502-508.

5. Reychler G, Wallemacq P, Rodenstein DO, Cumps J, Leal T, Liistro G. Comparison of lung deposition of amikacin by intrapulmonary percussive ventilation and jet nebulization by urinary monitoring. J Aerosol Med 2006;19(2):199-207.

6. Dellamonica J, Louis B, Lyazidi A, Vargas F, Brochard L. Intrapulmonary percussive ventilation superimposed on conventional ventilation: bench study of humidity and ventilator behavior. Intensive Care Med 2008;34(11):2035-2043.

7. Berlinski A, Willis JR. Albuterol delivery via intrapulmonary percussive ventilator and jet nebulizer in a pediatric ventilator model. Respir Care 2010;55(12):1699-1704.

8. Karashima T, Mimura-Kimura Y, Miyakawa K, Nakamura A, Shimahara F, Kamei H, Mimura Y. Variations in the efficiency of albuterol delivery and intrapulmonary effects with differential parameter settings on intrapulmonary percussive ventilation. Respir Care 2019; 64(5):502-508.

9. Klompas M, Branson R, Eichenwald E, Greene LR, Howell M, Lee $\mathrm{G}$, et al. Strategies to prevent ventilator-associated pneumonia in acute care hospitals: 2014 update. Infect Control Hosp Epidemiol 2014;35(8):915-936.

10. De Campo T, Civetta JM. The effect of short-term discontinuation of high-level PEEP in patients with acute respiratory failure. Crit Care Med 1979;7(2):47-49. 